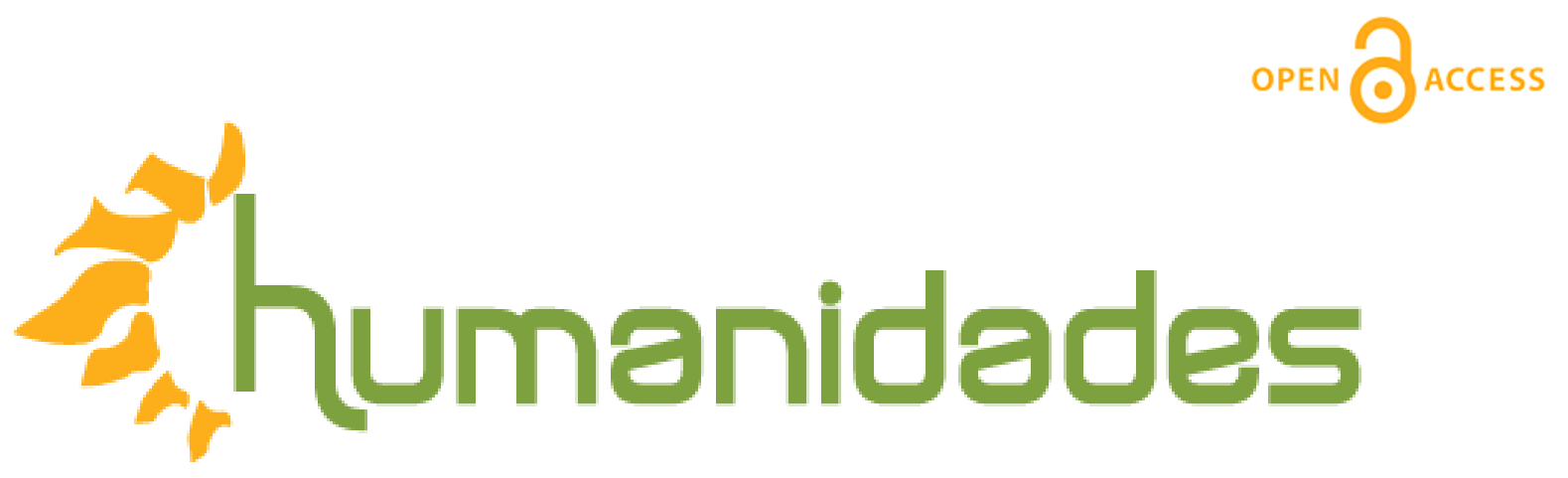

Revista de la Escuela de Estudios Generales, Universidad de Costa Rica

Julio-diciembre, 2016 • Volumen 6, número 2 • EISSN 2215-3934 • pp. 1-5

\title{
Pocas palabras sobre Cuentos de pocas palabras
}

DOI: http://dx.doi.org/10.15517/h.v6i2.26753

\section{Tatiana Herrera Ávila}

Profesora en la Escuela de Estudios Generales de la Universidad de Costa Rica.

Correo electrónico: tatiana.herrera@ucr.ac.cr

Todos los derechos reservados. Universidad de Costa Rica. Esta revista se encuentra licenciada con Creative Commons. Reconocimiento-NoComercial-SinObraDerivada 3.0 Costa Rica.

Correo electrónico: humanidades@ucr.ac.cr / Sitio web: http://revistas.ucr.ac.cr/index.php/humanidades 


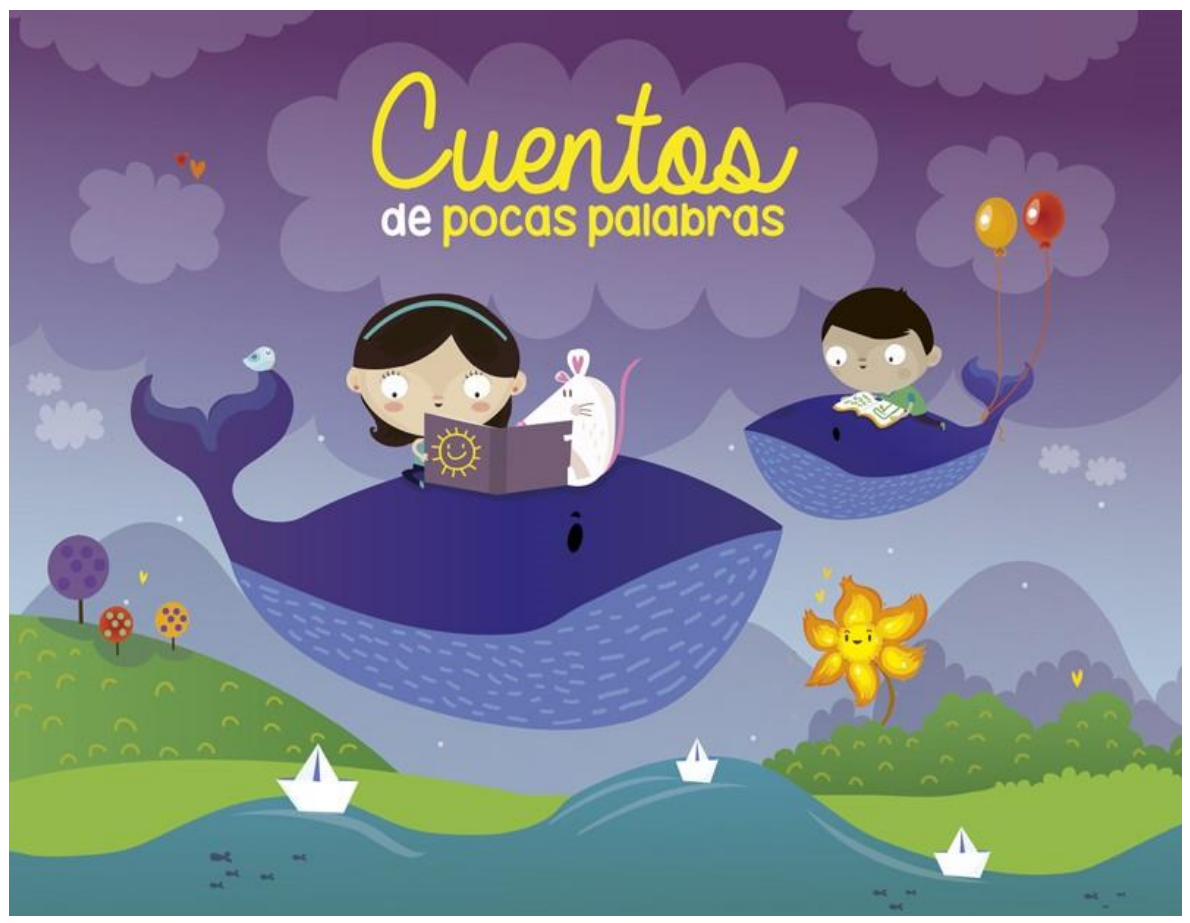

Leda Cavallini Solano

Cuentos de pocas palabras

San José, Costa Rica: Editorial Universidad de Costa Rica, 2015.

ISBN: 978-9968-46-479-6 
Si hay una literatura cargada de ideología, esa es aquella concebida para niños o que supone un lector joven, pues, a menudo, se encuentra enmarcada en visiones generalizadoras que pretenden ser didáctico moralizantes, pero que, más bien, terminan por reproducir prejuicios y por generar exclusiones.

Leda Cavallini, catedrática en la Escuela de Estudios Generales de la Universidad de Costa Rica, dramaturga e investigadora, se atreve a presentar, esta vez, una sensible propuesta de literatura para lectores jóvenes, desde el prisma de la inclusión de lo diferente, y se aleja de aquellos textos acartonados.

Esta escritora, de larga trayectoria, tiene a su haber el Premio Nacional de Teatro, ha figurado en varias ocasiones como jurado de los Premios Nacionales que otorga el Ministerio de Cultura y ha publicado varios textos teatrales, tales como Inquilinos del árbol, Tarde de granizo y musgo, Magnolia con almanaques, Ocho azucenas para nosotras mismas, así como dos novelas: Durante una flor con nombre de árbol y El hexágono de Andrupeto.

Adicionalmente, se destaca como promotora de la lectura infantil, ya que ha impartido varios talleres dirigidos a docentes, bibliotecólogos, niños y niñas.

Ahora bien, Cuentos de pocas palabras, título más que elocuente del nuevo libro de Cavallini, posee la estructura narrativa del microcuento y se inserta en la corriente de inclusividad y de apoyo a las personas con discapacidad. 
La utilización de dicha forma literaria sintética no es antojadiza o casual; esta responde a un homenaje a Tito Monterroso, célebre escritor guatemalteco de microcuentos, tal y como se señala en la contraportada del libro. A parte de esa expresa voluntad, también se puede anotar que la construcción del microrrelato convoca a la diversidad y convierte a estos cuentos, si se quiere, en un planteamiento sui generis ya desde la estructura misma, donde no vamos a encontrar el consabido cuento infantil que encasilla a su joven lector.

El cuento brevísimo, como también se denomina, se caracteriza por ser muy conciso y sumamente corto. Su estructura es sencilla, los personajes son escasos y levemente detallados, posee poca o ninguna descripción espaciotemporal y manifiesta una condensación de sentidos, la cual llama a la reflexión. Estos Cuentos de pocas palabras hacen justamente eso.

Ahora bien, la colección de cuentos se presenta, gracias a sus paratextos, como una herramienta de ayuda para la enseñanza de personas con discapacidad. Incluye, en virtud de esto, un "Apoyo legal sugerido al docente o a la docente para leer estos cuentos" (Cavallini, 2015, p. 30). En ese sentido, en cada uno de los cuentos se sugieren artículos del Código de la Niñez y la Adolescencia (Ley N. ${ }^{\circ}$ 7739), publicado en el 2004; de la Ley N. 7600 , sobre Igualdad de Oportunidades para las Personas con Discapacidad (2011); y de la Ley N. ${ }^{\circ} 8661$, sobre la Convención de los Derechos de las Personas con Discapacidad y su Protocolo Facultativo (2010). Lo anterior reviste a los textos de una clara intencionalidad de respeto a la diversidad y de una utilidad didáctica. 
Como es de esperar en un texto de literatura infantil, Cuentos de pocas palabras viene acompañado de ilustraciones muy llamativas, resultado de la cuidadosa edición del libro, a cargo de la Editorial de la Universidad de Costa Rica. La gráfica, a cargo de María José Da Luz, en definitiva coadyuva y complementa la lectura de estos cuentos.

Se podrían mencionar muchos asuntos sobre esta propuesta literaria; sin embargo, resulta más provechoso que sean sus lectores quienes se motiven a comentarla... a contar más, como se expresa en la contraportada del libro.

\section{¿Cómo citar este artículo?}

Herrera, T. (Julio-diciembre, 2016). Pocas palabras sobre Cuentos de pocas palabras. Revista humanidades, 6(2), 1-5. doi: dx.doi.org/10.15517/h.v6i2.26753 